\title{
PROPERTIES OF BOARDS MADE FROM RICE HUSK AND PORTLAND CEMENT AS BINDERS AND REINFORCED WITH SISAL FIBRES
}

\author{
Alex L. Mrema \\ Department of Structural and Construction Engineering, College of \\ Engineering and Technology, University of Dar es Salaam, P.O. Box \\ 35131, Tanzania. \\ email: alex.mrema@yahoo.com
}

\begin{abstract}
A research study demonstrated that rice husks can be used to manufacture boards which can be used in low cost housing if bound by Portland limestone cement (CEM II/A-L/ $32.5 R$ ) and reinforced with sisal fibers to cater for their brittle behavior and that such boards can provide a substitute for wood panels. Boards made of rice husks and cement in the ratios of $1 / 3.3,1 / 3.6$ and $1 / 4$ and with sisal fiber reinforcement contents of $0 \%, 0.4 \%$, $0.5 \%$ and $0.8 \%$ were prepared and tested for their physical and mechanical properties. The results were compared with standard requirements for boards made with wood based fiber and particle panel materials according to DIN 1101 and ISO 2696 and BS EN 634-2. Results indicate that water absorption and thickness swelling decreased with an increase in fiber content and that there is an optimum rice husk/ cement ratio and fiber content that gives maximum flexural strength and that such boards could be used in low cost housing construction. The use of such boards could be seen as partially solving the problem of global warming and the problem of pollution associated with the disposal of rice husks in developing countries.
\end{abstract}

Keywords: environmental pollution, global warming, rice-husk cement boards, sisal fiber reinforcement.

\section{INTRODUCTION}

Rice husk is the 'waste' material obtained from rice paddy after the extraction of the rice. About a tone of husk can be extracted from every five tons of paddy. In many countries particularly in the third world the husk is disposed of by dumping or burning and this causes environmental pollution. There is an increased concern on global warming due to deforestation and therefore an increased awareness of the use of natural fiber based building materials as a substitute for wood based fibers. The relatively high cost of manmade fibers and wire meshes used in fiber reinforced concrete and ferro-cement, combined with the elimination of asbestos as a reinforcement material due to health hazards has made it even more attractive to evaluate natural fibers as possible substitutes.

There exists large quantities of natural organic fibers in many third world countries and if properly exploited they can represent continuously renewable resources. The use of some of the best known fibers such as sisal and jute has been limited mostly to the production of fabrics, ropes and the like (Castro and Naaman, 1981). There has been little scientific effort devoted to the use of natural vegetable materials like rice husks and natural vegetable fibers as reinforcement for various building 
materials. This is unfortunate since some of the fibers show relatively high mechanical strengths. Sisal fibers have been reported to have tensile strengths of up to $689 \mathrm{MPa}$ and bamboo fibers to have tensile strengths of between $207 \mathrm{MPa}$ and $517 \mathrm{MPa}$. Moduli of Elasticity of between $14 \mathrm{GPa}$ and $28 \mathrm{GPa}$ has been encountered (Castro and Naaman, 1981).

A wide variety of fibers have been used with cement based matrices and these include metallic fibers, polymeric fibers, mineral fibers and vegetable fibers. The cement matrices normally consist of paste, mortar or concrete. Ordinary Portland cement has normally been used in these matrices. However, to improve durability of the composites or to minimize chemical interactions between the fibers and matrix, high alumina cement, cement with additives such as slag, silica fume, fly ash etc. have also been used (Gram, 1983; Todelo Filho, 1997).

Fibers are added to cement based matrices as primary or secondary reinforcement. In thin products where conventional reinforcement bars cannot be used, fibers can be added as primary reinforcement. In these applications the fibers increases both the strength and toughness of the composite. In components such as pavements and slabs fibers are added to control cracking induced by temperature variations or humidity and in these applications the fibers act as secondary reinforcement (Todelo Filho, 1997).

Vegetable fibers have been tried as reinforcement for cement matrices to produce low-cost thin elements for low cost housing in developing countries. Vegetable fibers require only a low degree of industrialization for the processing and in comparison with an equivalent weight of the most common synthetic reinforcing fibers, the energy required for the production is small and hence the cost of fabricating these composites is also low (Aziz et al., 1984). The use, however, of vegetable fibers, including sisal, bamboo, coconut, jute and wood fibers which are the prospective reinforcing materials has until now been more empirical than technical.

The behavior of cement based composites has extensively been investigated by England and Toledo Filho (1997). They observed that two major roles are played by the fibers and that is to improve the toughness and the post cracking performance of the matrices. They noted that there are some changes created to the the pre-cracking behavior of the hardened matrix which help to define the composite action. Fiber content ( $\%$ by volume), ratio of the fiber modulus to the matrix modulus and the ratio of the fiber strength to the matrix strength all influence the performance of the composite before and after cracking (Beaudoin, 1990; Todelo Filho et al., 1999). Bentur and Mindes (1990) observe that in a well designed composite the fibers can serve two functions in the post-cracking zone. The fibers increase the strength of the composite over that of the matrix by providing a means of transferring stresses and loads across the cracks and also increase the toughness of the composite by providing energy absorbing mechanisms related to the debonding and pull-out processes of the fibers bridging the cracks.

The properties of the fibers are important for design purposes. Normally the fiber strength is higher than the matrix strength and is influential in post cracking behavior only when long fibers are used (i.e. long enough to prevent complete pull out at the time of first cracking) or when one has a high matrix strength and uses a small volume fraction of fibers. A high ratio of fiber modulus to matrix modulus will facilitate stress transfer from the matrix to the fiber. If the fibers have large values of 
failure strain this will lead to a high extensibility in composites (Todelo Filho et al., 1999). Beaudoin (1990) suggests that problems associated with fiber debonding at the fiber-matrix interface are prevented by having a low Poisson's ratio of the matrix.

Studies of sisal fiber reinforced concrete were started by Nilsson (1975) in Sweden in 1971. In 1977 the Building Research Unit (BRU) in Dar es Salaam Tanzania collaborated with the Swedish Cement and Concrete Research Institute (Cappelen, 1978; BRU DATA SHEET, 1978; Mwamila, 1979; Mawenya and Mwamila, 1979; Mwamila, 1987) in the development of roof sheets using sisal fibers. A special roof sheet profile was developed and several buildings in Dar es Salaam Tanzania were provided with sisal fiber reinforced concrete roofs. The methods of extraction, microstructure and properties of sisal fibers have been discussed elsewhere (Joseph et al., 1999). The cement matrix normally consists of paste, mortar or concrete. There are various production technologies available (Bentur, and Mindess, 1990).

Several studies have been reported in literature based on the use of sisal as reinforcement in cement matrices (Aziz et al., 1984; Nilsson, 1975; BRS News, 1970; Zonsveld, 1975; Mukherjee and Satyanarayana, 1984; Gram, 1983). Swift and Smith [1978a; 1978b) found out that the use of sisal fibers as reinforcement in cement paste and concrete led to toughness in beams and that remarkably high strengths could be achieved using suitable mixing and casting techniques with optimum fiber volume fraction. The use of sisal fibers was also found to improve the impact resistance of the beams.

The objective of the investigation was to determine whether sisal fibers could be used to reinforce rice husk cement paste composites and if so what would be the optimum mix proportions of the ingredients. Previous pilot studies on unreinforced rice husk cement paste composites showed very high brittleness and very low flexural strengths of the composites and therefore there was a need to use sisal fibers as a reinforcing material.

\section{MATERIALS AND METHODS}

Rice husks, Portland limestone cement (CEM II/A-L/ 32.5R) and sisal fibers were obtained locally close to Dar es Salaam. Using a solar powered digital calliper (Digimatic solar 500-S15M) the lengths of the rice husks were determined from 15 measurements and an average length of $9.45 \mathrm{~mm}$ with a standard deviation of $0.82 \mathrm{~mm}$ was obtained. The bulk density of the husks was found to be $146.7 \mathrm{~kg} / \mathrm{m}^{3}$. The sisal fibers to be used were cut to a length of 5-6 cm. Longer fibers tend to curl and make mixing difficult.

Batching of the materials was done by weight. A mould measuring 300x300x15 $\mathrm{mm}$ was used to prepare the boards. Samples with the following mix proportions: rice husks to cement ratios of $1 / 3.3,1 / 3.6$, and $1 / 4$ and with sisal fiber contents of $0 \%, 0.4 \%, 0.5 \%$ and $0.8 \%$ by weight of cement were prepared and casted. About 1\% calcium chloride by weight of cement was used as an accelerator. In all the samples the water cement ratio was kept at 0.4 .

The mixing was done by first preparing a cement paste of water cement ratio of 0.4 . Rice husks and sisal fibers were then added to the paste little by little and mixing was done by hand to ensure that all the husks and sisal fibers were coated with the cement paste and that the mix was uniform with no segregation. From trial and error method it was established that to get the required board thickness of 
$15 \mathrm{~mm}$ a pressure of $0.017 \mathrm{MPa}$ was required. This pressure was applied to the samples for 24 hours before demoulding. This pressure also helped prevent resilience of the husks and therefore ensured a better bonding between the husks, sisal fibers and the cement paste. After the samples were removed from the moulds they were cured under water for twenty eight (28) days. Both physical and mechanical tests were performed on the specimens. Prior to testing the samples were trimmed, weighed and kept in an oven at a temperature of $105^{\circ} \mathrm{C}$ for 24 hours. Figure 1 shows some of the boards before testing.

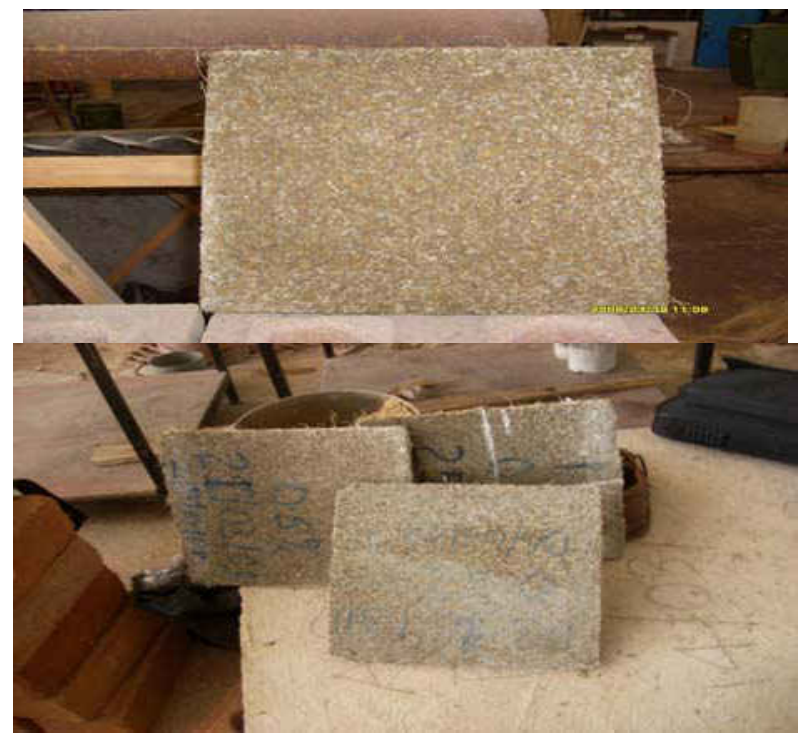

Figure 1: Some of the boards before testing

\section{RESULTS AND DISCUSSION}

The boards manufactured were found to have a density in the range of 700 to 1065 $\mathrm{kg} / \mathrm{m}^{3}$ which approximately falls within the range of high density boards (800 $1280 \mathrm{~kg} / \mathrm{m}^{3}$ ) (Youngquist et al., 1993). The water absorption of the boards is shown in Figure 2. for different Rice husk/cement ratios and sisal fiber contents. The values obtained were below the values recommended in ISO 2696 (1976) for hard and medium boards which is $30 \%$ and $40 \%$ respectively for $24 \mathrm{hrs}$ immersion in water. The results show a decreasing trend in water absorption as the sisal fiber content increases. The thickness swelling after 6 hours of soaking gave a similar trend (Figure 3 ). The reason for this trend is that the sisal fibers restrains the resilience of the rice husks in the matrix and therefore the more the amount of fibers you have in the matrix the higher the restraint and consequently the lower the water absorption and thickness swelling. All the boards showed thickness swelling values below $1.5 \%$ which is the maximum value recommended in BS EN 634-2: 1996 (2007).

The relationship between the Modulus of rapture (MOR) and sisal fiber content is shown on Figure 4.The maximum values obtained for Modulus of Rapture was with sisal fiber content of $0.5 \%$ and rice husks/cement content of $1 / 3.6$. This ratio may be considered as the optimum mixing proportions. The maximum MOR value of $5 \mathrm{MPa}$ obtained was, however, much smaller than the value of $39.2 \mathrm{MPa}$ that was obtained by Youngquist et al. (1993) by mixing rice husks, cement and bentonite binder which was a much stronger binder. The values were also less than $13.0 \mathrm{MPa}$, a minimum MOR value that is specified by BS 5669: 1989 Part 2 for General Purpose Boards. All the 
values of MOR obtained, however, exceed by far the minimum flexural strength requirement of $0.7 \mathrm{MPa}$ specified in DIN
1101: 1989 for wood wool slabs and sandwich composite panels for use as insulating materials.

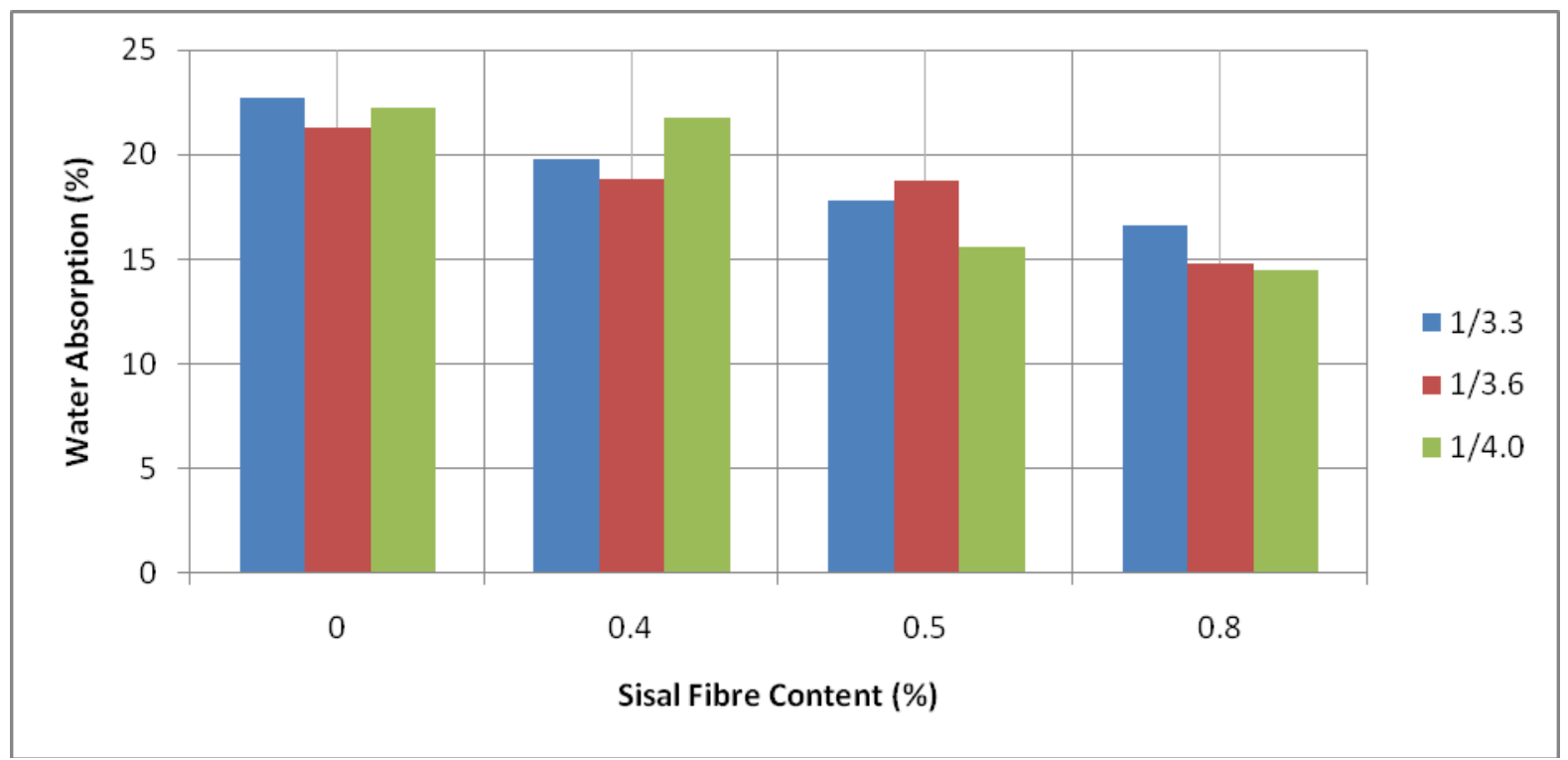

Figure 2: Relationship between Water absorption and Sisal Fiber Content for different rice Husk/Cement ratios

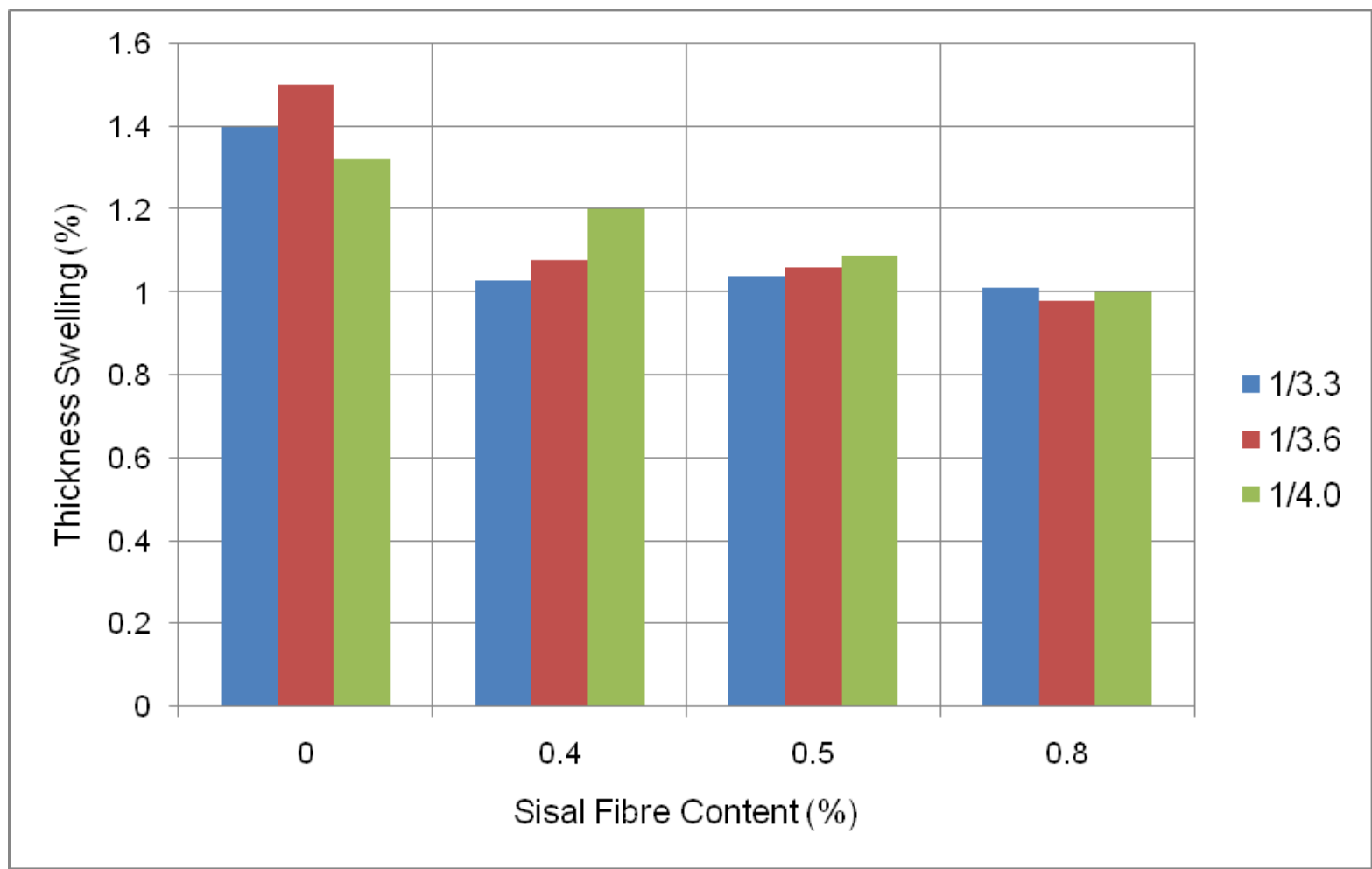

Figure 3: Relationship between Thickness Swelling and Sisal Fiber Content for different Rice Husk/Cement ratios 


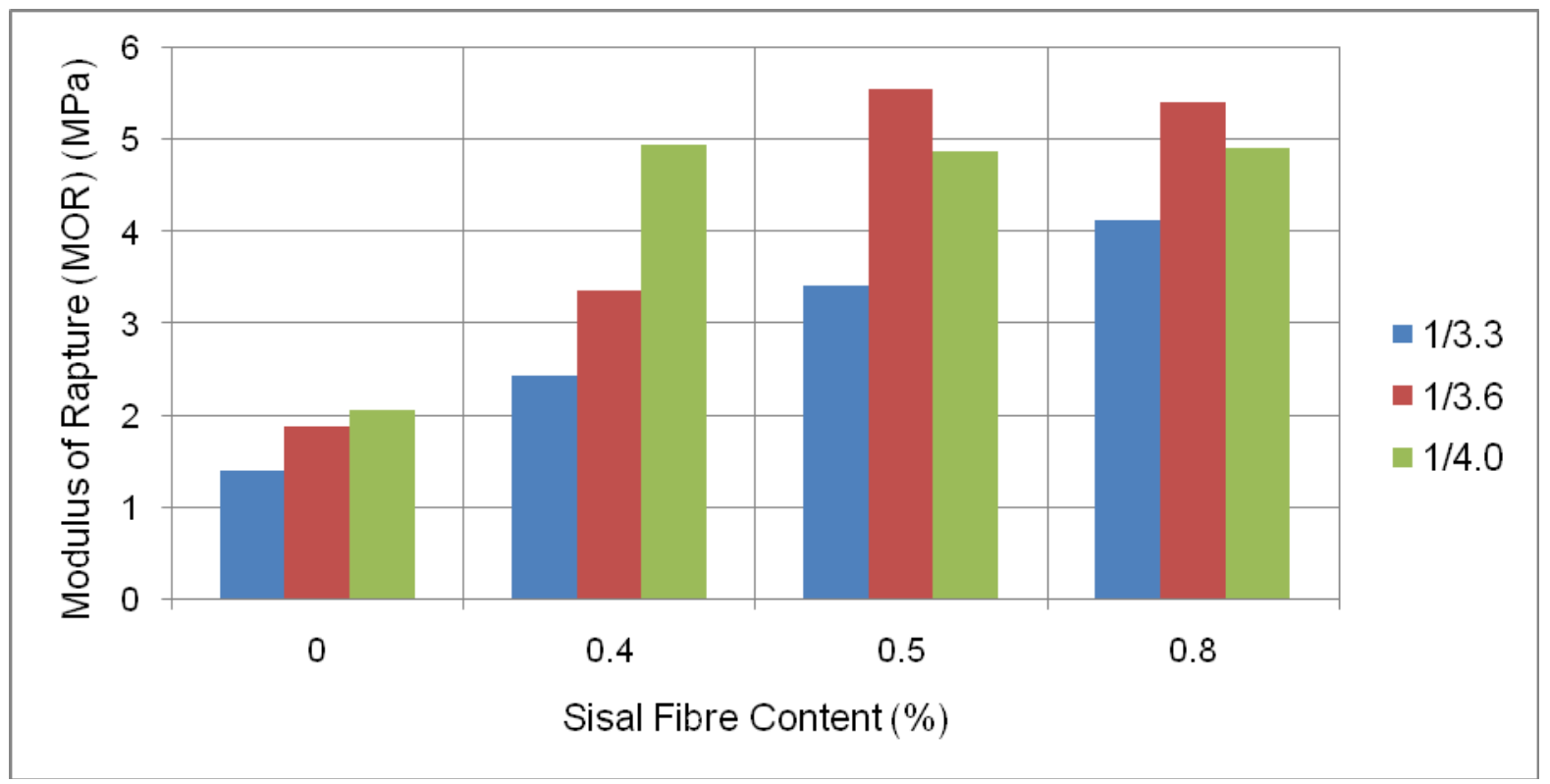

Figure 4: Relationship between Modulus of Rapture and Sisal Fiber Content for different rice Husk/Cement ratios

\section{CONCLUSIONS AND RECOMMENDATIONS}

It can be concluded that the boards manufactured fall in the range of high density boards. The water absorption of the boards was, as expected, below the recommended values in ISO 2696 for high and medium density boards. The water absorption and thickness swelling of the boards decreased with an increase of sisal fiber content. All the boards showed thickness swelling values below the $1.5 \%$ maximum value recommended in BS EN 634-2 (2007). The optimum mix proportions to give maximum flexural strength was found to be with a sisal fiber content of $0.5 \%$ and rice husk cement content ratio of $1 / 3.6$. Within the range of rice husk/cement and sisal fiber ratios tested, the values of MOR obtained far exceed the minimum requirement of $0.7 \mathrm{MPa}$ specified in DIN 1101:1989. This is consistent with observations made by Sandermann (1970) who observed that panels produced under prevailing local conditions are much better than those claimed by standards. The potential uses of such boards are in basements, floor units, permanent shuttering, partitioning, sound insulation in walls, ceilings and floors, roofs, sound barriers and thermal insulation. The use of such boards could be seen as partially solving the problem of global warming and the problem of pollution associated with the disposal of rice husks in developing countries. Further refinement of the research is required to determine optimum fiber lengths to be used and the optimum pressure to be applied on boards of different thicknesses. The use of alternative mineral binders should also be investigated.

\section{REFERENCES}

Aziz M.A., Paramasivam P. and Lee S.L. (1984). Concrete reinforced with natural fibers. In Swamy, R.N. (Ed.) Natural fiber reinforced cement and concrete. London: Blackie and Son Ltd, 5(3): 106-140.

Beaudoin J.J. (1990). Handbook of fiber reinforced concrete. U.S.A., Noyes Publications, 332p.

Bentur A. and Mindess S. (1990). Fiber reinforced cementitious composites. Elsevier Applied Science, U.K. 449p. 
Building Research Station News (BRS) (1970). Poor outlook for sisal, U. K., BRS News, No. 14.

BRU DATA SHEET (1978). Roof Sheets made of sisal reinforced concrete, Dar es Salaam, Tanzania, Building Research Unit, $1-8$.

BS EN 634 - 2 (2007). Cement-bonded particleboards. Specifications. Requirements for OPC bonded particleboards for use in dry, humid and external conditions.

Cappelen P. (1978). Roof sheets made of sisal reinforced concrete, Building Research Unit, Ministry of Lands Housing and Urban Development, Tanzania, Working Report, WR14, $1-7$.

Castro J. and Naaman, A.E. (1981). Cement Mortar Reinforced with Natural Fibers. ACI Journal, 78: 6978.

DIN 1101: (1989). Wood wool slabs and sandwich composite panels for use as insulating materials. Requirements and testing, EURO 96.40.

England G.L. and Toledo Filho R.D. (1997). Natural fiber reinforced concrete. In: Asia-Pacific Speciality Conference on fiber reinforced concrete. Singapore, 55-70.

Gram H.E. (1983). Durability of Natural Fibers in Concrete. Swedish Cement and Concrete Research Institute, Research Fo. 1:83, 225p.

ISO 2696 (1976). Fiber building boards Hard and medium boards for general purposes- Quality specifications Water absorption and swelling in thickness.

Joseph K., Toledo Filho R.D., James B., Thomas S. and Carvalho, L.H. (1999). The use of sisal fiber as reinforcements in polymer in composites, Brazilian Journal of Agricultural and Environmental Engineering.

Mawenya A.S. and Mwamila B.L.M. (1979). Characteristics of sisal as a reinforcing fiber, Faculty of
Engineering, University of Dar es Salaam, 1-22.

Mukherjee K.G. and Satyanarayana K.G. (1984). Structure and properties of some vegetable fibers, Part 1: Sisal fiber. Journal of Materials Science, London, 19: 3925-3934.

Mwamila B.L.M. (1979). Flexural behavior of concrete elements reinforced with sisal fibers. Dar es Salaam, MSc Thesis, University of Dar es Salaam, Tanzania.

Mwamila B.L.M. (1987). Characteristics of natural fibrous reinforcement in cement - based matrices. Symposium on building materials, for low income housing, Bangkok, Thailand, Jan. 20 - 26, 87-93.

Nilsson R. (1975). Reinforcement of concrete with sisal and other vegetable fibers. Stockholm: Swedish Council for Building Research, 68p. Document No. D - 14

Sandermann W. (1970). Technical processes for the production of woodwool cement boards and their adaptation for utilization of agricultural wastes. Expert working group meeting on the production of panels from agricultural wastes, Vienna, Austria, 14-18 December, 1970.

Swift D.G. and Smith R.S.L. (1978a). Sisal fiber reinforcement of cement paste and concrete, In: Materials for construction for developing countries, Bangkok, 221-233.

Swift D.G. and Smith R.S.L. (1978b). Sisal-cement composites as low cost construction materials. Appropriate Technology, London, 6(3): 6-8.

Toledo Filho R.D. (1997). Natural Fiber reinforced mortar composites: Experimental characterization, Rio de Janeiro: DEC/PUC, 472p. Ph.D. Thesis.

Toledo Filho R.D., Joseph K., Ghavami K. and England G.L. (1999). The use of sisal fiber as reinforcement in cement based composites. Revista 
Brasileira de Engenharia Agricole e Ambiental, 3(2): 245-256.

Youngquist J.A., English B.E., Spelter H. and Chow P. (1993). Agricultural fibers in Composition panels. Proceedings of the $27^{\text {th }}$ International Particleboard/ Composite Materials Symposium, Washington State
University, Pullman, WA. USA, 133152.

Zonsveld J.J. (1975). Properties and testing of concrete containing fibers other than steel. In: Rilem Symposium on fiber reinforcement and concrete, London, The Construction Press, 217-226. 